This item was submitted to Loughborough's Research Repository by the author.

Items in Figshare are protected by copyright, with all rights reserved, unless otherwise indicated.

\title{
Where do the limits of experience lie? Abandoning the dualism of objectivity and subjectivity
}

PLEASE CITE THE PUBLISHED VERSION

http://dx.doi.org/10.1177/0952695108093954

PUBLISHER

(c) SAGE Publications

VERSION

AM (Accepted Manuscript)

LICENCE

CC BY-NC-ND 4.0

\section{REPOSITORY RECORD}

Greiffenhagen, Christian, and Wes Sharrock. 2019. "Where Do the Limits of Experience Lie? Abandoning the Dualism of Objectivity and Subjectivity”. figshare. https://hdl.handle.net/2134/13252. 
This item was submitted to Loughborough's Institutional Repository (https://dspace.lboro.ac.uk/) by the author and is made available under the following Creative Commons Licence conditions.

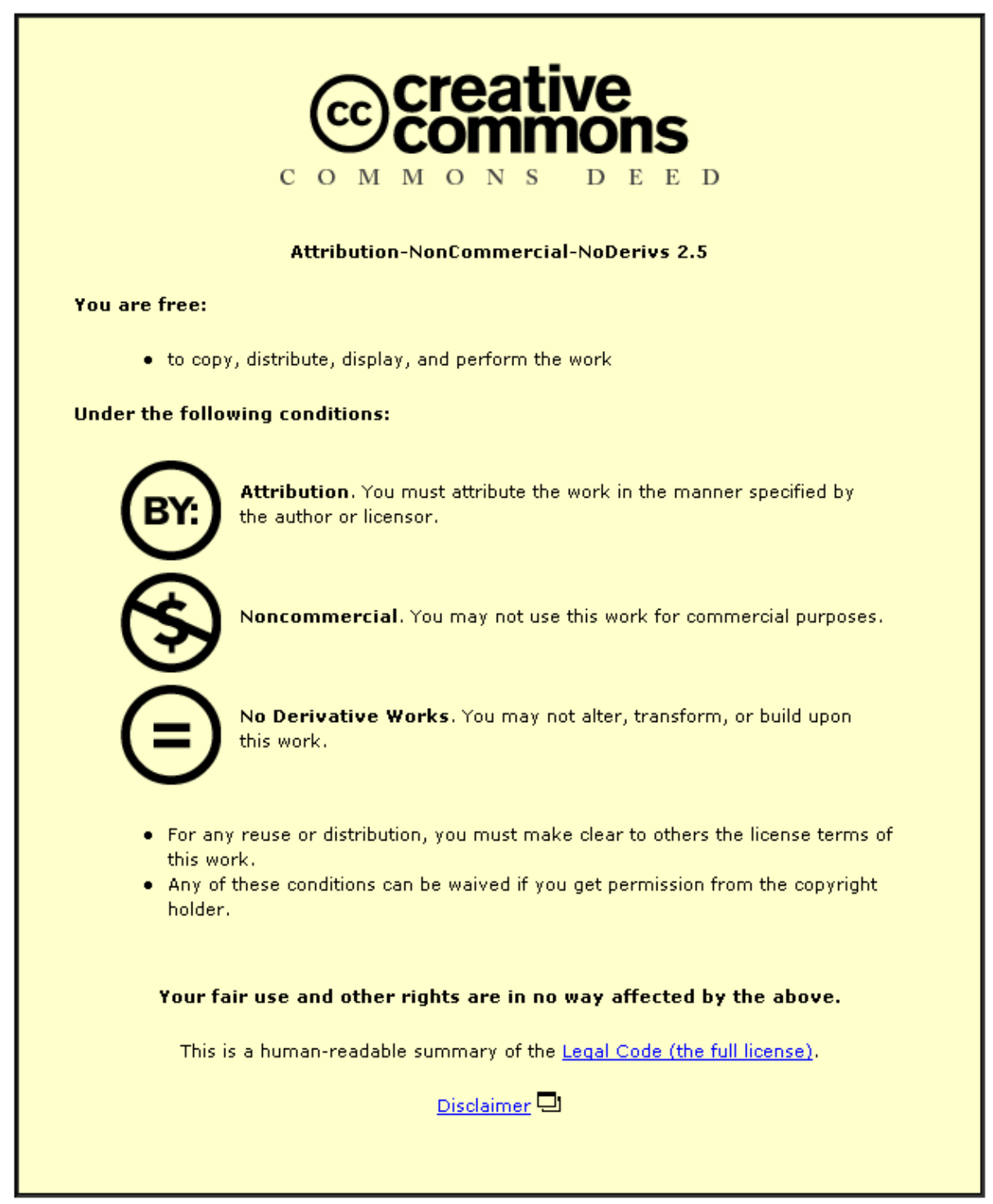

For the full text of this licence, please go to: http://creativecommons.org/licenses/by-nc-nd/2.5/ 


\section{Where do the limits of experience lie?}

\section{Abandoning the dualism of objectivity and subjectivity}

Authors: Christian Greiffenhagen and Wes Sharrock

Address:

Christian Greiffenhagen

Department of Sociology

Arthur Lewis Building

University of Manchester

Manchester M13 9PL

UK

Email: Christian.Greiffenhagen[replace_with_@]manchester.ac.uk

Version: January 23, 2008 


\title{
Where do the limits of experience lie?
}

\section{Abandoning the dualism of objectivity and subjectivity}

\begin{abstract}
The relationship between 'subjective' and 'objective' features of social reality (and between 'subjectivist' and 'objectivist' sociological approaches) remains problematic within social thought. Phenomenology is often taken as a paradigmatic example of subjectivist sociology, since it supposedly places exclusive emphasis on actors' ‘subjective' interpretations, thereby neglecting 'objective’ social structures.
\end{abstract}

In this article, we question whether phenomenology is usefully understood as falling on either side of the standard divides, arguing that phenomenology's conception of 'subjective' experience of social reality includes many features taken to be 'objective' elements of it. We illustrate our argument by a critical examination of Jean Lave's attempt to differentiate social practice theory from phenomenology. We show that many theoretical positions that want to overcome the subjective-objective dualism retain an objectivist conception of the 'subjective’ features of social reality.

\section{Keywords}

phenomenology; social practice theory; objectivity; subjectivity; objectivism; subjectivism; Jean Lave; Pierre Bourdieu 


\title{
Introduction
}

The recent understanding of the history of sociological thought is that for a period it was divided over the nature of social life's most fundamental dimensions. That division involved polarised opposition between two separate vocabularies, one made up of terms such as 'structure', 'object', ‘totality', ‘determinism', and 'macro', whilst the other prized 'agency', 'subject', ‘individual', ‘spontaneity', and 'micro'. These vocabularies were frequently treated as mutually exclusive, i.e., one had to think of social reality either according to the first or to the second collection of terms. As Hays (1994, p.57) puts it:

\begin{abstract}
One of the most prevalent forms of contrast is that between 'structure and agency'. [...] this contrast is often mapped onto another set of dichotomies common in social theorizing and interpreted to mean, for instance, that structure is systematic and patterned, while agency is contingent and random; that structure is constraint, while agency is freedom; that structure is static, while agency is active; that structure is collective, while agency is individual.
\end{abstract}

In the sociological literature, the contrast between 'structure' versus 'agency' is perhaps the most prevalent one (cf., Sewell, 1992; Hays, 1994; Alexander, 1995; Archer 1995; Bhaskar, 1998; Rubinstein, 2001; King, 2004; Sawyer, 2005). Another way of expressing many of these differences is by opposing 'objectivism' to 'subjectivism', which will be our concern here. The following quotation shows the supposition that the contrast between individuals and structures can be mapped onto divergences amongst sociological positions:

The split between subjectivism and objectivism has led to two theoretical constituencies that rarely account for each other [...]. Those scholars who focus on the individual, his or her knowledge, actions, intentions or goals, leave the nature of the 'world' or environment relatively unexplored. 
Those in the other set emphasise the world and its structures, while individuals and social structures are assumed to exist as uniform entities. (Osterlund and Carlile, 2005, p.92)

Osterlund and Carlile reflect an understanding in which objectivism and subjectivism are seen as two discontinuous sociological approaches, i.e., as logically and empirically independent of each other. Subjectivist approaches (such as, supposedly, symbolic interactionism, phenomenology, or ethnomethodology) are seen to focus on personal or individual experience and therefore supposedly overlook, neglect, or even flatly deny the relevance of macro-structural phenomena to sociological understanding. In contrast, objectivist approaches (for example, Marxism, functionalism, or critical theory) aim to adopt an external or transcendent viewpoint and therefore seem to exclude actors' personal or individual experience.

In these discussions, it is important to note that various kinds of levels or questions are often mixed up, in particular, ontological (What are the basic units of a sociological theory, individual actors or social structures?), epistemological (How can social science know reality?), and methodological (How should social science study reality, e.g., through 'subjective' accounts or 'objective' statistics?). In an important sense, the difference between subjectivism and objectivism often boils down to the question: Is reality represented in individuals’ perceptions or is reality something external to them?

Objectivism assumes that social reality cannot be reduced to subjects' experience of it. Objectivism in sociology does not necessarily employ the appearance/reality duality in the Kantian sense of the inaccessibility of the thing-in-itself, but rather affiliates the dualism with the understandings and methods of social science. For objectivists, it is typically only members of society (subjects) who are restricted to dualism of objectivity and subjectivity. History of the Human Sciences 21 (3), 70-93. 
(subjective) appearances, whereas neutral, external, scientific (objective) observers do have access to (objective) reality. According to the objectivist picture, an approach like phenomenology is subjectivist, since it takes (subjective) appearances for (objective) realities:

[...] phenomenology is even more radical in its rejection of social structures as external and constraining. How the social world appears to the individual is the only legitimate topic for the social analyst to study. This is the only reality; anything else is an artificial construction of sociologists. (Layder, 2006, p. 92; our emphasis)

Both subjectivism and objectivism have been criticised for their reductionism. Consequently, many theorists have questioned the mutual exclusivity of subjectivist and objectivist terminologies and have wondered whether a compromise is possible, i.e., whether they can be combined in a unified sociological scheme. Among the most prominent approaches that have tried to transcend the subjective-objective dualism are Bourdieu’s (1977) social practice theory, Giddens’ (1979) structuration theory, and Habermas’ (1984/1987) life-world and system scheme.

In this paper we argue that such attempts at synthesis characteristically retain an objectivist position. That is to say, the characterisation of approaches such as phenomenology as 'subjectivist' presupposes an underlying subjective-objective dualism, which phenomenology explicitly aims to overcome. We thus follow recent papers by Throop and Murphy (2002) and Endress (2005) who have defended phenomenology against the accusation (especially by Bourdieu) of subjectivism.

Jean Lave's social practice theory and her study of shopper's decision-making during grocery shopping (e.g., Lave, 1988; Lave et al., 1984; Lave and Wenger, 1991) serves as our illustrative example of an integrationist approach, which draws explicitly on dualism of objectivity and subjectivity. History of the Human Sciences 21 (3), 70-93. 
Bourdieu and Giddens and their critique of phenomenology as subjectivist (Lave, 1988, pp.15-18; Lave and Wenger, 1991, p.50). Since her empirical study is based on participant observation (following shoppers around in supermarkets) and is therefore similar to what phenomenologists might do, this case allows comparison of the theoretical, methodological, and practical differences between social practice theory and phenomenology.

\section{Phenomenology's alleged subjectivism}

Lave's approach is an example of a widespread tendency to characterise phenomenology as ‘subjectivist'. For example, Bunge (1993, pp. 210-211) states:

Subjectivism is the philosophical view that the world, far from existing on its own, is a creation of the knowing subject. [...] A clear modern example of subjectivism is phenomenology.

Clegg (1983, p.114) claims that Schutz “developed a radically subjectivist sociology”; Martin (2000, p.210) argues that Habermas rejects "the subjectivism of phenomenology and ethnomethodology”; Hewitt (2003, p.17) writes that "Phenomenological sociology makes the subjective standpoint of individual actors its central focus of attention”, which results in a position of "extreme subjectivity" (p. 19); and Layder (2006) claims that “phenomenology takes a rather more subjective stance” (p.92), while “[e]thnmethodology [takes] an even more radically subjective approach” (p.103).

Social theorists frequently take the perceived subjectivism of phenomenology to imply that phenomenology denies the existence of 'objective' social structures. In other words, phenomenology is seen either (a) as claiming that actors are completely free to act in, or form interpretations of, the world, or (b) as denying that any features 
beyond the immediately perceivable here-and-now affect actors' actions. Thus Bunge (1993, p. 211) states that phenomenology and ethnomethodology "focus on individuals and deny the real existence of social systems and macrosocial facts”. Layder (2006, p.108) claims:

\begin{abstract}
[...] phenomenology has tended to [...] denying the role of structural factors beyond the observable and empirical 'local practices' that constitute the subject matter of social analysis. Ethnomethodology, in particular, has adopted this view, suggesting that it is indifferent to, and suspends belief in, institutions, classes, organisations - in short all the phenomena associated with structural studies. [...] The pose of 'indifference' to any 'level' of analysis simply masks a very decided bias towards the analysis of micro phenomena and an inability to cope analytically with macro phenomena like power, structures and institutions. In particular, the notion of constraint in social life is considerably underplayed while freedom of choice, the ability to create meaning and to pursue purposes are seemingly unhindered by larger structures of domination.
\end{abstract}

It is phenomenology's alleged dispensation with the independent reality of social structures (and the implication that there is nothing external to the individual will to act as a 'constraint' on what the will commands) that most puzzles objectivists. We think that such a view involves an underestimation of phenomenology and is based on the attribution of a double naïveté, first to subjects, then to phenomenologists.

Objectivists assume, firstly, that subjects are naïve in comparison to sociologists. Subjects are seen either as presupposing that their actions are entirely spontaneous, making them oblivious to the given sociocultural conditions that form their dispositions to act and provide the circumstances which 'constrain' their actions. Alternatively, subjects are seen as imagining that how they (the subjects) see social reality is how it 'really is', implying that subjects mistake a particular, situated dualism of objectivity and subjectivity. History of the Human Sciences 21 (3), 70-93. 
viewpoint for a comprehensive, complete one. That is to say, subjects are seen as assuming that their momentary situations are the sole reality and are therefore blind to the ways in which momentary situations stand in relation to geographically expansive and temporally protracted complexes of socioeconomic relationships. Subjects either have an implausibly voluntarist conception of their powers and/or fallaciously generalise their limited perspectival experience of a miniscule locale to the totality.

Objectivists not only ascribe these twin forms of naïveté to subjects, but argue, secondly, that phenomenologists are naïve in accepting subjects' subjectivity as their (the phenomenologists') guide to the nature of social reality. In the eyes of objectivists, since phenomenology starts and remains with subjects' experiences of the social world, phenomenology will be unable to avoid adopting subjects’ naïve focus on their respective 'here-and-nows' and will have to neglect all imposed, predetermining, and restricting conditions. A possible base for attributing this second naïveté can be found in Schutz, who insists that

[...] the constructs of the social sciences are, so to speak, constructs of the second degree, that is, constructs of the constructs made by the actors on the social scene, whose behaviour the social scientist has to observe and to explain in accordance with the procedural rules of his science. (Schutz, 1962, p.59)

Schutz argues that social scientists have to start with actors' interpretations of the social world, which for objectivists seems not only a serious restriction for social science, but in fact condemns social science to subjectivism, substituting actors' subjectivist interpretation for social reality. 
For example, Bourdieu, who has been particularly influential in characterising phenomenology as subjectivist, critiques Sartre's supposedly subjectivist phenomenological approach thus ${ }^{1}$ :

If the world of action is nothing other than this universe of interchangeable possibles, entirely dependent on the decrees of the consciousness which creates it and hence totally devoid of objectivity, if it is moving because the subject chooses to be moved, revolving because he chooses to be revolted, then emotions, passions, and actions are merely games of bad faith, sad farces in which one is both bad actor and good audience [...]. (Bourdieu, 1977, p.74; emphasis in original) ${ }^{2}$

For Jenkins (1992, p.17) this shows that Bourdieu wants to argue that there is "more to social life than the subjective consciousness of the actors who move within it and produce it. There is, if you like, an objective social reality beyond the immediate interactional sphere and the self-conscious awareness of individuals.” Bourdieu argues that social scientists must not pursue a subjectivist approach, but also seems to suggest that subjects themselves are subjectivist in this way. Thus Bourdieu goes on to quote from Durkheim's The Rules of Sociological Method:

It is because the imaginary offers the mind no resistance that the mind, conscious of no restraint, gives itself up to boundless ambitions and believes it possible to construct, or rather reconstruct, the world by virtue of its own strength and at the whim of its desires.

\footnotetext{
${ }^{1}$ See Harcourt (2006) for a more recent critique of phenomenology along Bourdieu’s line.

${ }^{2}$ When evaluating Bourdieu's, as well as Harcourt's (2006), characterisation of Sartre it is important to bear in mind that although Sartre uses the term 'subjective', this does not necessarily imply that Sartre supposes that individuals can do whatever they want, only - to put it very crudely - that they have the power to say 'no' to situational pressures to act in bad faith.
} dualism of objectivity and subjectivity. History of the Human Sciences 21 (3), 70-93. 
Here Bourdieu seems to imply that Sartre's doctrine, while wrong as a starting point for social science, nevertheless correctly portrays subjects' subjectivity, i.e., captures subjects’ naïve conviction that they are free to act however they will. Bourdieu does not challenge that part of Sartre's doctrines, but criticises Sartre for appropriating that naïve standpoint as his theoretical one, infringing Bourdieu’s maxim that:

One is entitled to undertake to give an 'account of accounts', so long as one does not put forward one's contribution to the science of pre-scientific representation of the social world as if it were a science of the social world. (Bourdieu, 1977, p. 21)

The core of our argument can thus be given as a summation of these themes: objectivists believe, firstly, that subjects are subjectivist; and, secondly, that phenomenology necessarily acquiesces in subjects' subjectivism. Phenomenology’s denial of subjectivism puzzles objectivists: “Aren’t you saying that you are taking actors' perspectives seriously? Well, if they are subjectivist, then so must you be!” However: Are subjects 'subjectivist' as envisioned by objectivists - or is this only an artefact created by overburdening the characterisation of subjectivity with objectivist preconceptions? Objectivists imagine that phenomenology quarrels with objectivists’ characterisation of phenomenology, whereas the real quarrel is with objectivists' treatment of subjects. Thus in our view neither subjects nor phenomenologists are subjective in the sense outlined.

As mentioned, Throop and Murphy (2002) and Endress (2005) also criticise Bourdieu's characterisation of phenomenology and defend phenomenology at the level of doctrine. Both articles point out that Bourdieu exaggerates the differences between his own theory and phenomenology and document that propositions which Bourdieu insists must be constitutionally absent from phenomenology are explicitly dualism of objectivity and subjectivity. History of the Human Sciences 21 (3), 70-93. 
present there. This is a correct reaction against the second form of naïveté described above, whilst our strategy is to cast doubt also on the first.

We have used the term 'phenomenology' rather indiscriminatingly so far, possibly implying that phenomenology is a single, coherent approach. Throop and Murphy (2002, p.189) criticise Bourdieu for his overly inclusive use of the term 'phenomenology' and we might seem open to a tu quoque.

Phenomenology is typically taken to originate with Edmund Husserl (1931, 1970) who had an immense influence on, inter alia, Heidegger and Merleau-Ponty (see Spiegelberg, 1960). For the social sciences, the works of Aron Gurwitsch (1964) and Alfred Schutz (1962, 1964, 1966) have been particularly important. Schutz's work consisted in the application of some of Husserl's policies in the preparation of a philosophical prologue to a sociology of social action and has been popularised in the social sciences by Berger and Luckman’s (1966) The Social Construction of Reality, while Harold Garfinkel's (1967) Studies in Ethnomethodology involved a complex transformation of Schutz (and others) into an empirical sociological approach. While these authors share some similarities (most importantly an indebtedness to Husserl), they are clearly not part of a unified project. However, within the social sciences, the differences between them are often ignored, i.e., 'phenomenology' often functions as a gloss for all of them (and sometimes might even include references to symbolic interactionism or Goffman). In particular, there is typically no distinction made between Husserl's phenomenology, Schutz's (social) phenomenology, and Garfinkel’s ethnomethodology (see, e.g., Bourdieu, 1977, p.3; Bunge, 1993, pp. 210212; Martin, 2000, p.210; Layder, 2006, pp. 106-109). Since in this paper we are only 
interested in the implied subjectivism of, e.g., Schutz's phenomenology or Garfinkel's ethnomethodology, we use the term 'phenomenology' in a similar way.

\section{Phenomenology's complaint}

As just explained, we are critical of the portrayal of phenomenology as subjectivist, a portrayal which plays such an important part in the manufacture of an 'integrationist' problem for sociological theory. It is striking, however, that this view is not only common among objectivists, but also among those approaches that are not wholly unsympathetic to phenomenology's objectives and, in particular, agree with phenomenology's critique of some forms of objectivism. Such approaches include, for example, activity theory (Engeström, 1999, 2001), social practice theory (Schatzki et al., 2001, Chaiklin and Lave, 1993), or situated learning theory (Lave and Wenger, 1991). While seeing some promise in phenomenology, these approaches argue that phenomenology's contribution to sociological analysis can only be partial, since there are aspects of the social world that are beyond phenomenology's reach. Consequently, phenomenology cannot stand alone, but must be supplemented by some historical, structural, or other account. Phenomenology enables some valid objections to objectivism but goes too far. Such approaches agree with Bourdieu that the opposition of objectivity and subjectivity is a key dualism that sociology must confront. Objectivist sociology wrongly focused only on 'objective' features of social reality and phenomenology appropriately corrected this. However, phenomenology overreacted, moving away from objectivity to focus entirely on subjectivity.

We quoted Layder (2006, p. 92) who argued that "phenomenology is even more radical in its rejection of social structures as external and constraining”. Layder is correct in thinking that phenomenology is radical, but not in the sense that it moves 
from social structures to individual agency, but in the sense that it collapses the distinction. Phenomenology does not simply change the focus of study, but rather makes the original dichotomy superfluous. Within the objectivist tradition (and its dualist successors) it is assumed that the properties that an object possesses 'objectively' and the properties of the object 'subjectively' perceived are discontinuous. In contrast, phenomenology argues that the disjunction is an artefact of the fact that the object-as-perceived is only portrayed in a superficial and partial manner. Giving up the initial dualism results in a more scrupulous portrayal of experience, including the 'objective' features inherent in experience. In Kantian terms: objectivists accept a fundamental difference between the 'objective' object-initself and the 'subjective' object-in-experience. Phenomenology does not restrict itself to the study of only one of two possible objects (the object-in-itself or the object-in-experience), but rather questions the duplication. For phenomenology there is one object, not two, and that is the object-in-experience (cf., Garfinkel, 1952, pp. 95-97), where that object-in-experience has the essential features objectivists ascribe to the object-in-itself ${ }^{3}$. This means that resolutely faithful portrayal of the 'subjective' is equally resolute and faithful in portraying the 'objective'.

This is perhaps more easily appreciated, if it is realised that the designation of the object-in-experience is not a locative. It therefore does not involve an ontological relocation, transporting, e.g., the 'objective' chair in the corner of the room to a new

\footnotetext{
${ }^{3}$ See, for example, Garfinkel (2002), where ethnomethodology is characterised as a translation of the properties of Durkheim's social facts into practically produced organisational features of everyday phenomena (see also Greiffenhagen and Sharrock, forthcoming b).
}

Greiffenhagen, C. and W. Sharrock (2008). Where do the limits of experience lie? Abandoning the dualism of objectivity and subjectivity. History of the Human Sciences 21 (3), 70-93. 
site inside an individual's head or into the realm of ideas. From the perspective of phenomenology, 'objective' properties of the chair (for example, that it remains in place and does not change its form whether or not I am present in the room), is not something that is only available to sociologists, but is part of the way the chair is experienced by actors. Schutz's famous example of the house (1962, p. 108) was used to point out that our experience of the house is not restricted to what is currently in our visual field.

In an early paper, Bittner (1973) resisted the characterisation of phenomenology as subjectivist, since such a characterisation leads to an 'aborted' phenomenology, one that would remain caught in the subjective-objective dualism it aims to overcome. Bittner argued that although phenomenology investigates subjects' experience of the world, this experience is not construed to be purely 'subjective', since it includes many references to an 'objective' social world (which phenomenologists sometimes try to express by speaking of 'the intentionality of consciousness'). Bittner pointed out that Schutz's analysis begins from 'the world of everyday life', and that Schutz emphasises that an important feature of the world of everyday life is precisely that it is experienced as spatially and temporally extended ${ }^{4}$. Schutz argues that subjects' experiences, while the starting point for a social science of action, are not solipsist in nature, but include references to an external social world that is experienced as shared

\footnotetext{
${ }^{4}$ Objectivists often suppose that the concept of 'totality' is indispensable to sociological thought, but this is perhaps because they think that the object of inquiry is 'the society' (often equivalent to the nation-state), which might be amenable to 'totalising', but whilst 'the world of everyday life' features some large-scale organisations (the nation-state itself among them), it does not seem amenable to the kind of synoptic totalisation that objectivists envisage.
}

Greiffenhagen, C. and W. Sharrock (2008). Where do the limits of experience lie? Abandoning the dualism of objectivity and subjectivity. History of the Human Sciences 21 (3), 70-93. 
with others (who are known predominantly through typicality and with varying degrees of specificity and determinacy). As Bittner (1973, p.120) puts it:

[i]t is impossible to overestimate the centrality of the subject for the phenomenal constitution of the world of everyday life. But while I am undeniably the center, the 'null-point', toward which the world of everyday life is structured, I recognize within this world, through the office of the general thesis of the alter ego, you, him, them, all 'nullpoints' in their own rights. And so the world of everyday life is above all our home in which we live, in some ways identically, similarly, jointly, reciprocally, according to arrangements some of which we claim to have authored whereas others appear to belong to preexisting realities.

Bittner is aware of the danger that his view could be characterised as subjectivist. He provides the following warning:

To say that the world of everyday life is organized relative to the perceiving subject seems to imply that its meaning structures are freely determined at this 'null-point'. To counteract this possible implication it will be worthwhile to draw attention to the ways in which the factual reality of the world actually impresses its hold on the subject.

First, I, the perceiving subject who faces the world knowingly, know that as an object among objects I enjoy no special privilege. I come into being, endure and perish as a thing among things and even if I have it within me to look forward to redemption, it will not be in this world. However much I may have taken charge of my own life, the bare fact of my existence is just that, a fact over which I have no control. [...]

Second, despite the fact that I have (together with the rest of mankind, of course) an enormous span of control over the world surrounding me [...], it remains a melancholy truth that the world as a whole will always have its way with me, in the long run. [...] What else is folly if not the neglect of or oblivion to the intractabilities of the world? (p. 120; our emphases)

Bittner gives voice to the phenomenological view that the experience of the world begins with the subject. However, Bittner points out that this leaves in place the fact dualism of objectivity and subjectivity. History of the Human Sciences 21 (3), 70-93. 
that the world "impresses its hold on the subject" and that there are many aspects over which one has no control. Bittner resists precisely the two forms of naïveté outlined. Both subjects and phenomenologists are aware of 'objective' features in experience and aware that the experienced world is predominantly not under the control of the subject. What makes Bourdieu-type conceptions 'abortive' for Bittner is that they delete the central task of phenomenology's inquiries, which does not turn attention inward to 'the subject', but seeks faithfulness to 'the objects' that are found in experience, a procedure which if conducted effectively does not deprive 'objects' of their objective character, but achieves an appreciation of how objectivity is present in experience.

\section{An illustrative case}

We will try to clarify some of the issues by focussing on an example, the work of Jean Lave, who takes pains to distance her 'integrationist' social practice theory from phenomenology and who indicates general approval of Bourdieu's position in these matters (Lave, 1988, pp.15-18; Lave and Wenger, 1991, p.50).

Lave’s famous study was the Adult Math Project (e.g., Lave, 1986, 1988, 1993; Lave et al., 1984, 1989; de la Rocha, 1985, 1986; Murtaugh, 1985a,b), in which arithmetic practices were studied in everyday situations, including, supermarket shopping, dieting, and cooking. Methodologically, the approach of the supermarket study was participant observation:

[...] we followed participants at times when they fit shopping into their schedules (any hour of the day or night). We arrived at the house in time to observe preparations for shopping, went to the store together, shopped, and returned home to follow the process of storing groceries as the expedition ended in their kitchens. (Lave, 1988, p.49) 
The data were obtained through participant observation. Before entering the supermarket, shoppers strapped a tape recorder over their shoulder and were asked to 'think aloud' while proceeding through the store, because the two anthropologists accompanying them were interested in learning about their shopping procedures, whatever they might be. As a shopper walked through the store, one researcher maintained a running conversation with the shopper. (Lave et al., 1984, p.69)

Like Suchman (1987), Lave offered a consequential critique of formalistic and cognitivistic conceptions of cognition and learning, emphasising their practical and situated nature (viz. the title of her book, Cognition in Practice). The aim of the supermarket study was to demonstrate that arithmetic practices rather than 'driving' shopping decisions, were shaped by them: "Arithmetic problematic-solving is thus [...] strongly shaped in form, outcome, and meaning by the broader scope of activity and setting within which it occurs” (Lave et al., 1984, p.68).

We find Lave's interpretations of the Adult Math Project's case studies questionable (see Greiffenhagen and Sharrock, forthcoming a), but the interest here is in how Lave frames the case studies within a social practice theory. The emphasis on the practical and situated nature of activities might have suggested affinity with phenomenology and ethnomethodology, but Lave is anxious to minimise this:

The characteristic focus of practice theory on individuals in activity in social interaction suggests strong ties with ethnomethodological or other phenomenologically-based theories. But practice theory focuses on everyday activity in human-scale institutional realizations of sociocultural order. Principles of production and political organization are incorporated through the analysis of how they present themselves to the experience of individuals in the arenas of everyday action in the world. Practice theory, which treats macrostructural systems as fundamental, and focuses on relations between structure and action, is thus not to be confused with a phenomenological view, which treats social systems as (only) 
epiphenomena of intersubjectively constituted experience. That both focus analysis on the details of everyday practice should not obscure the essential difference between them (Lave, 1988, p. 193, endnote 7).

Further:

The phenomenological position enjoys continuity between socially relating individuals and the society they interactively construct. But correspondingly, it is unable to account for macro-social, politicaleconomic structures which, it appears, individuals can neither create nor negotiate directly but which somehow contribute to the public aspect of specific contexts. [Phenomenology] has [...] experience without system. (Lave, 1988, p.150)

In these quotations we find the view outlined above: a perceived fundamental contrast between, on the one hand, "principles of production and political organization” (i.e., objective social structures), and, on the other, “the experience of individuals” (i.e., subjective agency). Since phenomenology focuses only on the latter, "it is unable to account for macro-social, political-economic structures”.

\section{The attribution of naïveté}

According to Lave, both social practice theory and phenomenology focus on “individuals in activity”, taking seriously individuals' experience of the situation. However, phenomenology looks at this alone and therefore must neglect social structures that influence this experience. In contrast, social practice theory focuses on “macrostructural systems" and investigates relations between these and subjects' experience of them. Phenomenologists are thus seen as naïve vis-à-vis social practice theorists, since they ignore macro-social structures. Phenomenology is not mistaken to pay attention to individuals' experiences (this it shares with social practice theory), but is wrong to do so at the expense of social structures. Social practice theory, whilst also focussing on individuals, does not make this mistake. 
Lave exhibits the aforementioned objectivist conception of experience, understood as limited to the here-and-now with an implied distinction between "principles of production and political organisation" in themselves, and how these "present themselves to the experience of individuals". There is therefore also the naïveté of individuals vis-à-vis analysts, where only the latter have 'objective' access to "principles of production and political organization”. In other words, it is not just phenomenologists, but also subjects, who do not see the 'objective' features of the situation. This can briefly be illustrated by Lave's description of the nature of choices to be made during a shopping trip:

The supermarket is thought of by consumers as a locus of abundant choices, for which the stock of thousands of items constitutes apparent evidence. But contradicting this view is a different order of circumstances: the shopper cannot provide food for the family if he leaves the supermarket empty-handed, due to attacks of indecision. That is, the shopper, faced with abundant alternatives, nonetheless cannot avoid making choices. Conversely, because the making of choices cannot be avoided, it is to the seller's advantage to proliferate decision criteria in the shopping setting. This contributes to the shopper's experience of abundant choices, helping to maintain the contradiction between choice and the necessity of choosing. This contradiction is not itself generally recognized, much less viewed as problematic, by shoppers. (Lave et al., 1984, pp.79-80; our emphases)

Here a contrast is made between the appearance of the benefits of "abundant choices", which supposedly stands in contradiction to the necessity of “making choices”. The described situation seems obvious enough: on the one hand, it is nice that when buying a particular kind of product (e.g., yoghurt), shoppers have a few alternatives to choose from. On the other hand, shoppers may wish to minimise the time spent shopping, so the availability of alternatives can be seen to complicate the shopping process. However, note that Lave attributes naïveté to shoppers, since she argues that dualism of objectivity and subjectivity. History of the Human Sciences 21 (3), 70-93. 
this ‘contradiction' "is not itself generally recognized [...] by shoppers” (though known to the analyst). Since shoppers are limited to (subjective) experiences of the supermarket, they do not see these (objective) aspects of it.

Lave also distinguishes between the perspective of shoppers and the perspective of sellers. That, again, seems an obvious point: what shoppers 'want' from the supermarket is different from what sellers 'want' from the supermarket. We might even say that these wants stand, in a certain sense, in contradiction to each other (shoppers want to pay as little as possible, whereas sellers want to charge the highest price). In that sense, shoppers' and sellers' experiences of supermarkets differ. Lave may think that it is this difference that is unrecognized as problematic by shoppers (and phenomenologists). In contrast, we argue that shoppers understand this. For example, if the supermarket increases the price of an item, shoppers' experience includes the 'conflict' between their and the supermarkets' needs. Shoppers appreciate the ‘contradiction’ observed by social practice theory (and consequently, so can phenomenologists).

In sum, Lave asserts the superiority of social practice theory over both phenomenology and the experience of subjects themselves. However, this superiority is based on the ascription of naïveté to both phenomenologists and shoppers, where this ascription is not the result of the analysis, but an a priori overruling.

\section{The durable and non-negotiable character of social structures}

This is further illustrated by Lave's characterisation of what seems to objectivists the most fundamental aspect of social structures: their durability and non-negotiability. While (subjective) experiences are seen as fleeting, short-lived, and malleable, (objective) structures are seen as persistent, enduring, and immutable. It is the 
resulting 'constraint' of objective structures on subjective experience that phenomenology supposedly ignores or cannot account for. Whilst the experience of the supermarket as part of the shopping trip is transient, the supermarket 'in itself' remains before and after the shoppers' presence there. Furthermore, while shoppers may 'negotiate' their experience of the supermarket, the supermarket 'in itself' cannot be (directly) influenced by shoppers:

Certain aspects of behavior settings have durable and public properties. The supermarket is such a durable entity - a physically, economically, politically, and socially organized space-in-time. In this aspect it may be called an 'arena' within which activity takes place. The supermarket as arena is the product of patterns of capital formation and political economy. It is not negotiable directly by the individual. It is outside of, yet encompasses the individual, providing a higher-order institutional framework within which the setting is constituted. At the same time, for individual shoppers the supermarket is a repeatedly experienced, personally ordered and edited version of the arena. In this aspect it may be termed a 'setting' for activity. Some aisles in the supermarket do not exist for a given shopper as part of his setting, while other aisles are multifeatured areas to the shopper who routinely seeks a particular familiar product. (Lave et al., 1984, p.71; our emphases)

Lave argues for a difference between the supermarket seen 'subjectively' (as 'setting') and 'objectively' (as 'arena'). This illustrates that objectivists assume that the properties that an object possesses 'objectively' and the properties of the object 'subjectively' experienced are discontinuous, as Lave assumes a fundamental difference between the supermarket's durable, standardised, impersonal, and public properties with the ways it is experienced as part of individuals' personally ordered shopping trajectories. 
Note that Lave's description of supermarkets seems to consist of two relatively unremarkable Durkheim-style points. Firstly, the supermarket business involves a large plurality of participating individuals, both of the same category (different shoppers) and of different categories (e.g., shoppers and sellers). Therefore the supermarket cannot be reduced to the experience and activities of any single one of those. In other words, the object 'the supermarket' is not identical with any one individual's singular or repeating experience and in that sense exists externally to individuals’ personal experience.

Secondly, the object 'the supermarket' is not controllable by single individuals, or at least only marginally so. That is, the nature of the supermarket imposes itself on the shopper's experience rather than the other way around. The shopper is powerless to affect the overall organisation of the supermarket company, must mostly comply with the corporate requirements as to the form of shopping procedures, and individually can engender only the most insignificant of effects upon the corporately formatted layout and functions of the shop's floor.

For Lave these observations seem to be important, presumably because she feels that phenomenologists (or shoppers) might deny them. In contrast, we see these observations as uncontroversial, i.e., would argue that both shoppers and phenomenologists are aware of them. In particular, phenomenology does not deny that the supermarket "is not negotiable directly by the individual”, but argues that the difference between the 'negotiable' and the 'non-negotiable' is made within experience (and inherent, so to speak, in the structure of action, or, to highlight just this feature, of action conceived as practical). In other words, a non-aborted conception of experience subsumes both of Lave's observations. 
Three points follow: Firstly, those aspects of supermarkets that Lave labels “a nonnegotiable concrete realization of a political economy" are not available to phenomenology through a study of shoppers' experience, but that does not mean that phenomenology could not capture these by studying other individuals (e.g., managers, architects, engineers, marketing people, etc.).

Secondly, many of the 'non-negotiable' aspects of supermarkets are nevertheless available to shoppers, especially if they take an interest in them. In other words, these features may be beyond (direct) 'control', but not beyond 'intelligibility'. Even if you haven't studied supermarkets, you are probably aware of taken-for-granted understandings of supermarkets, such as that they strive to make profits, that products are arranged to prompt impulsive purchasing, or that products are placed in prominent positions as 'loss leaders'.

Thirdly, although these aspects may be beyond immediate and direct control of individual shoppers, they are not necessarily completely beyond their influence. In other words, in Lave's claim that these aspects are "not negotiable directly by the individual”, there is no specification of the extent to which they are non-negotiable, i.e., over what time span, in relation to what other activities and concerns, and through what co-ordination with others ${ }^{5}$. Complaining to the manager about the danger to children of a given product's placement might occasion immediate re-arrangement of the store floor, just as threatening litigation on the basis of some candidate negligence

\footnotetext{
${ }^{5}$ As King (1999, p. 221) notes: “Thus, although it is true that 'I' as an individual can do practically nothing and that material conditions seem glacial to me, it is not true that these conditions are independent of everybody and that everybody can do nothing.”
} dualism of objectivity and subjectivity. History of the Human Sciences 21 (3), 70-93. 
can occasion instant relaxations of corporate policies. Participating in publicised boycotts or signing consumer-lobby petitions are, of course, projects with longer-term effects (aimed at modifying supermarket policies) and are thus not to be accomplished during today's shopping trip (and it is in terms of the latter that we are being invited to identify 'the arena' that is the supermarket).

The very question of what features of the supermarket count as 'negotiable' thus depends on which individuals, projects, circumstances and time spans we are talking about. Things that are inflexible givens for a brief shopping trip are not necessarily such in the context of commitment to a collective project of boycotting supermarket goods and protesting locations. Lave sees the difference in negotiability in ontological terms, resulting in a difference between the supermarket as 'setting' and as 'arena', where the former is available to shoppers and the latter to sociologists. In contrast, we have been arguing that the difference in negotiability lies in the nature of the practical tasks and associated means involved (for example, between making day-today purchasing selections in the light of one's domestic circumstances and participating in collective activities aimed at confounding corporate management). These differences do not reflect differences between actors and sociologists, but between different kinds of actors engaged in different kinds of activities.

\section{Methodological or literary differences?}

We had mentioned above that social practice theory, whilst sharing with phenomenology a focus on individuals, thinks that it can avoid phenomenology's mistake of doing so at the expense of social structures. This raises the question: How does social practice theory (or other approaches that are dismissive of phenomenology) achieve this? 
Sometimes the differences between objectivist and subjectivist sociological approaches are framed in terms of different methods of empirical investigations and resultant data. For example, those who argue for a primacy of social structures often emphasize the importance of surveys or other representations of large and distributed populations, while thus focusing on agency may prefer participant observation of a few specific individuals. However, the differences between Lave's social practice theory and phenomenology are not based on methodological differences of this kind. Lave's study of supermarkets is conducted through participant observation featuring in situ interviews with shoppers, which is hardly different from materials that phenomenologists could - indeed did (see Hester and Francis, 2003) - assemble.

This raises the question: How does Lave access objective social structures in a way which differs from that in which anyone or phenomenologists might do? She argues that social practice theory "treats macrostructural systems as fundamental, and focuses on relations between structures and action” (Lave, 1988, p. 193, endnote 7). However, what method does Lave have to access and identify "macrostructural systems” in themselves? In particular, are these methods different from those that individuals (shoppers, sellers, etc.) use to attend to them? If the supermarket's structure is not directly findable by individuals, how is Lave able to locate the properties she invokes?

Lave does not directly answer these questions. However, since she does not provide any substantial or systematic data on the arena-structure of supermarkets, it seems most likely that the supermarket as 'arena' (that is contrasted with the supermarket as 'setting') in Lave's argument must itself be constructed from common-sense understandings. In other words, Lave’s appeals to 'supermarkets' do not evidence dualism of objectivity and subjectivity. History of the Human Sciences 21 (3), 70-93. 
previously undocumented data, but are presented as reasonable and recognisable everyday claims about 'what supermarkets are really like' (that are plausible independently of any research documentation). Lave's supermarket as 'arena' is neither more nor less than the-supermarket-that-everyone-knows ${ }^{6}$, stereotypically known as organised to make profits, maximise sales, surreptitiously stimulate consumer expenditure, and so on. For example, when Lave (1986, p.95) writes that:

The store has won many of the agonistic struggles for the cultural formulation of supermarket arenas - most information considered vital to shoppers is in very small print; prices are given as prime numbers, making calculation difficult; a whole series of strategies in placing and pricing products are notoriously favourable to management in the war between store and shoppers.

This observation is no summary of 'investigative journalism', where a reporter or researcher might present the reader with possibly novel revelations, but rather draws on knowledge shared with readers. Lave takes for granted readers' agreement that the store (management) is motivated by 'capitalist' rather than 'altruistic' concerns, and that the store is 'against' rather than 'for' shoppers ${ }^{7}$.

${ }^{6}$ As Sacks (1975) explained, ‘everyone’ is an indexical.

${ }^{7}$ This is further subversive of the dualism of objective structures and subjective experience, for it shows that 'social reality' is not two objects, differentially known to sociologists and members of society, but one object, the world of daily life, known under two (partially) distinct forms of practice. It seems to us that the sociologist's and members' actual relationship to the world of daily life (as opposed to the programmatically idealised one) is not between 'expert' and 'person in the street' (to borrow Schutz's scheme for the social distribution of knowledge), since what sociologists do (especially in an age of critical theory) is much closer to the practice of 'the well informed citizen'. In this paper we indicate how Lave's grasp of the empirical organisation of supermarkets is not based in dualism of objectivity and subjectivity. History of the Human Sciences 21 (3), 70-93. 
Lave's rhetorical contrast with phenomenology proposes an ontological difference between structure and agency and a difference between sociologists and actors, whereas we would argue that these differences are achieved through literary tropes. Lave's treatment of her supermarket materials resembles what Burke (1945, pp. 7790) has identified as 'changing the circumference', which consists of redefining the setting against which an action is portrayed in order to change the sense of that action. For example, rather than viewing a visit to the supermarket against the background of daily chores (its place in the round of housework, getting kids to school, etc.), it is reimagined against the capitalist system as a totality (therefore portraying the trip to the supermarket as an externally necessity imposed by capitalism). By this change in perspective, shoppers' understandings of their supermarket visits are transformed into misunderstandings, since their characterisations of the shopping trip conflict with those of the analyst. However, the source of shoppers' 'misunderstandings' is not their subjectivity (and the implied objectivity of the analyst), but rather a result of the fact that the analyst has reframed the relevances against which shoppers' descriptions have to be understood. For example, witness how Lave deals with shoppers' characterisation of the shopping trip as 'routine':

Shoppers describe themselves as engaged in a routine chore, making habitual purchases. But their description must be addressed as data, not as part of the analysis. 'Habit' and 'routine' should be treated not as empirical descriptions of repeated episodes of the same activity in the

technical expertise of the political economy or operating structures of corporate supermarket chains, but in something like a consumer activist's 'well informed' grasp of contemporary public issues concerning supermarkets. dualism of objectivity and subjectivity. History of the Human Sciences 21 (3), 70-93. 
same setting but as statements of an ideological order. (Lave et al., 1984, p.77)

Through talking to shoppers before, during, and after their trip to the supermarket, Lave finds out that shoppers describe their shopping as 'routine', which is seen as evidence that shoppers experience the shopping trip as routine or habitual. Following Bourdieu's maxim to be dissatisfied with first-order descriptions, Lave wants to ask: Is the shopping trip really (objectively speaking) the way it is experienced?

As mentioned, Lave's overall targets are cognitive science conceptions of 'rationality' and 'problem solving'. For Lave, such theories conceive of calculation in terms of “mechanical reproduction” (Lave et al., 1984, p.77), e.g., see calculation as an entirely thoughtless activity (that could be done by a computer). In response, Lave holds that shopping does involve complex problem solving and decision making (e.g., when and where to calculate or choosing situation-specific means for calculation) and consequently should not be characterised as 'routine'.

Lave correctly rejects simplistic conceptions of rationality. However, she uses these theories to evaluate shoppers' descriptions of their shopping trip. For Lave, shoppers’ characterisation of the shopping trip as 'routine' shows that they accept the cognitivist conception of rationality. It must therefore be a "statement of an ideological order" and demonstrates that shoppers have 'internalised' the cognitivist ideology of rationality (cf., Lave, 1993, pp. 29-30; see Lynch, 1995, pp. 588-589). However, it is only by altering the circumference of 'routine' to cognitivist theories that Lave is forced to see shoppers as naïve. If we choose the circumference as 'other activities that we engage in', then there are good reasons why the shopping trip should be characterised thus: going to the supermarket to buy groceries is done frequently and often in standardised ways, making it more 'routine' than other activities, such as dualism of objectivity and subjectivity. History of the Human Sciences 21 (3), 70-93. 
buying a house or planning a holiday, which occur infrequently and may involve more complications.

Lave's strategy of 'changing the circumference' enables a final point with respect to the relationship of first- and second-order descriptions. As Lave demonstrates, social practice theory does not want to ignore individuals' (first-order) descriptions, but “their description[s] must be addressed as data, not as part of the analysis”. In other words, Lave agrees with Bourdieu’s maxim (already quoted) that

One is entitled to undertake to give an 'account of accounts', so long as one does not put forward one's contribution to the science of pre-scientific representation of the social world as if it were a science of the social world. (Bourdieu, 1977, p. 21)

Lave follows Bourdieu in her treatment of concepts such as 'choice', 'negotiability', or 'routineness'. Although she sees promise in talking to subjects, she does not want to take what subjects say at face value, since she assumes there to be a fundamental difference between (first-order) 'pre-scientific' and 'scientific' representations of the social world. For Lave, since phenomenology only focuses on subjects’ pre-scientific understandings, it cannot achieve a scientific one ${ }^{8}$.

\footnotetext{
${ }^{8}$ First-order understandings extensively feature typifications which can be more or less vague, detailed and anonymous. This carries an implication that ethnomethodology, rather more than Schutz, elaborates: a great deal of professional sociological reasoning does not use second-order constructs alone, but deploys these in conjunction with formally unacknowledged first-order typifications (which Bittner [1965] calls 'auxiliaries'). Categories like 'woman', ‘adult', ‘employee', ‘manager', 'supermarket', etc. are first-order constructs, not second-order ones (see also Rose, 1960). Lave writes as if she was making reference to a set of well-developed sociological constructs - 'theories of capital formation', 'organizational development', etc. - but she mostly operates in terms of first-order ones.
} dualism of objectivity and subjectivity. History of the Human Sciences 21 (3), 70-93. 
We have argued that a comparison of (first-order) 'pre-scientific' with 'scientific' representations can only be effective if the character of the former is faithfully rendered. We have tried to demonstrate that the difference between the pre-scientific 'setting' and the allegedly scientific 'arena' neither consists in the availability of more data nor is it derived from methods available uniquely to professional researchers, but rather depends upon disregarding those relevancies that might make the shoppers' assessments of their grocery shopping experience both cogent and apt in favour of theorist-imposed standards of relevance. Lave counters an extreme form of cognitivism that insists that all activities are matters of mechanical routine by arguing that no activities are routine. Whilst shoppers' shopping practices can thus serve Lave's counter-cognitivist argument (since they can be seen as complex and nonmechanical), shoppers' experience of what they are doing as routine stands in conflict to Lave's characterisation of it. Despite officially aiming to vindicate the competence and sophistication of 'just plain folks', Lave actually treats shoppers as naïve about their own experience, but does so by disregarding evidence that the cognitivists' conceptions are not those shoppers themselves have in mind.

In sum, the 'inadequacy' of (first-order) 'pre-scientific' representations is not usually determined by reference to the representational roles that such constructs play in their home environment, the world of everyday life and its practical affairs, but through pre-emptive determination of the relevances such representations must satisfy. Objectivists suppose that the easy part is establishing what 'subjective understandings' are, whilst phenomenologists know that this is not so. 


\section{Conclusion}

Attempts to unify sociological thought in a situation of bifurcation are mostly undertaken on the basis that an insurgent subjectivism has entailed an illicitly reductive treatment of the objectivity of social structures. Unifications are therefore pre-eminently directed toward resisting any kind of reductionism to the 'subjective' and to make sure that they can account for 'objective' features of social life. In contrast, we have argued for a more sceptical attitude toward the need for (and possibility of) any unification on those terms. We have tried to show that the concern for the objectivity of social structures involves a relentlessly reductive treatment of 'the subject', one constructed more to enable the programme of unification on the assumptions of objectivism than to enable even-handed participation from, e.g., phenomenology. Objectivists misunderstand phenomenology as a doctrine that argues that the world is experienced as subjective (with the implication that the experienced world is divested of objective properties). In contrast, we have tried to show that phenomenology's starting assumption is that the world is experienced as objective, i.e., that it is experienced as possessing just those properties - of externality, independence, publicity durability, immutability - that objectivists treasure.

If our arguments are correct, then overcoming the subjective-objective dualism is not merely a matter of adjusting a picture which has become crooked (an image suggested by one unsympathetic reviewer), but of rearranging a whole gallery of them. A typical conception of this dualism seems to be that it has split the (whole) picture of reality into two parts which now have to be carefully glued together again. Instead, we have argued that the initial drawing may have already been flawed. 


\section{Acknowledgements}

We thank the editor and four anonymous reviewers for helpful comments on an earlier draft. Christian Greiffenhagen acknowledges support from the British Academy (a Postdoctoral Fellowship and Small Research Grant) and Wes Sharrock support from the Arts and Humanities Research Board (award number B/IA/AN10985/APN17690). 


\section{References}

Alexander, J. (1995). Fin de Siècle Social Theory: Relativism, Reduction and the Problem of Reason. London: Verso.

Archer, M. S. (1995). Realist Social Theory: The Morphogenetic Approach. Cambridge: Cambridge University Press.

Berger, P. L. and T. Luckmann (1966). The Social Construction of Reality: A Treatise in the Sociology of Knowledge. New York: Doubleday.

Bhaskar, R. (1998). The Possibility of Naturalism: A Philosophical Critique of the Contemporary Human Sciences (Third Ed.). London: Routledge.

Bittner, E. (1965). The concept of organization. Social Research 32 (3), 239-255.

Bittner, E. (1973). Objectivity and realism in sociology. In G. Psathas (Ed.), Phenomenological Sociology: Issues and Applications, pp. 109-125. New York: John Wiley \& Sons.

Bourdieu, P. (1977). Outline of a Theory of Practice (Translated by R. Nice). Cambridge: Cambridge University Press.

Bunge, M. (1993). Realism and antirealism in social science. Theory and Decision 35 (3), 207-235.

Burke, K. (1945). A Grammar of Motives. Englewood Cliffs, NJ: Prentice-Hall.

Chaiklin, S. and J. Lave. (1993). Understanding Practice: Perspectives on Activity and Context. Cambridge: Cambridge University Press.

Clegg, S. (1983). Phenomenology and formal organizations: a realist critique. Research in the Sociology of Organizations 2, 109-152.

de la Rocha, O. (1985). The reorganization of arithmetic practice in the kitchen. Anthropology and Education Quarterly 16 (3), 193-198.

de la Rocha, O. (1986). Problems of Sense and Problems of Scale: An Ethnographic Study of Arithmetic in Everyday Life. Ph. D. thesis, University of California, Irvine.

Endress, M. (2005). Reflexivity, reality, and relationality: the inadequacy of Bourdieu's critique of the phenomenological tradition in sociology. In M. Endress, G. Psathas, and H. Nasu (Eds.), Explorations of the Life-World: Continuing Dialogues with Alfred Schutz, pp.51-74. Dordrecht: Springer.

Engeström, Y. (1999). Activity theory and individual and social transformation. In Y. Engeström, R. Miettenen and R.-L. Punamaki (Eds.), Perspectives on Activity Theory, pp. 19-38. Cambridge: Cambridge University Press.

Engeström, Y. (2001). Expansive learning at work: toward an activity theoretical reconceptualization. Journal of Education and Work 14 (1), 133-156.

Garfinkel, H. (1952). The Perception of the Other: A Study in Social Order. Ph. D. thesis, Harvard University.

Garfinkel, H. (1967). Studies in Ethnomethodology. Englewood Cliffs, NJ: PrenticeHall.

Garfinkel, H. (2002). Ethnomethodology's Program: Working Out Durkheim's Aphorism. Lanham, MD: Rowman \& Littlefield. 
Giddens, A. (1979). Central Problems in Social Theory: Action, Structure and Contradiction in Social Analysis. Basingstoke: Macmillan.

Greiffenhagen, C. and W. Sharrock (forthcoming a). School mathematics and its everyday other? Revisiting Lave's 'Cognition in Practice'. Educational Studies in Mathematics.

Greiffenhagen, C. and W. Sharrock (forthcoming b). Mathematical equations as Durkheimian social facts? In G. Cooper, A. King, and R. Rettie (Eds.), Sociological Objects: The Reconfiguration of Social Theory. Ashgate.

Gurwitsch, A. (1964). The Field of Consciousness. Pittsburgh, PA: Duquesne University Press.

Habermas, J. (1984/1987). The Theory of Communicative Action (Two Volumes) (Translated by T. McCarthy). Cambridge: Polity.

Harcourt, B. E. (2006). Language of the Gun: Youth, Crime, and Public Policy. Chicago: University of Chicago Press.

Hays, S. (1994). Structure and agency and the sticky problem of culture. Sociological Theory 12 (1), 57-72.

Hester, S. and D. Francis (2003). Analysing visually available mundane order: a walk to the supermarket. Visual Studies 18 (1), 36-46.

Hewitt, J. P. (2003). Self and Society: A Symbolic Interactionist Social Psychology (Ninth ed.). Boston: Allyn and Bacon.

Husserl, E. (1931). Ideas: A General Introduction to Pure Phenomenology (Translated by W. R. B. Gibson). London: Allen and Unwin.

Husserl, E. (1970). The Crisis of European Sciences and Transcendental Phenomenology: An Introduction to Phenomenological Philosophy (Translated by D. Carr). Evanston, Ill: Northwestern University Press.

Jenkins, R. (1992). Pierre Bourdieu. London: Routledge.

King, A. (1999). Against structure: a critique of morphogenetic social theory. The Sociological Review 47 (2), 199-227.

King, A. (2004). The Structure of Social Theory. London: Routledge.

Lave, J. (1986). The values of quantification. In J. Law (Ed.), Power, Action and Belief: A New Sociology of Knowledge?, pp. 88-111. London: Routledge.

Lave, J. (1988). Cognition in Practice: Mind, Mathematics, and Culture in Everyday Life. Cambridge: Cambridge University Press.

Lave, J. (1993). The practice of learning. In S. Chaiklin and J. Lave (Eds.), Understanding Practice: Perspectives on Activity and Context, pp. 3-32. Cambridge: Cambridge University Press.

Lave, J., M. Murtaugh, and O. de la Rocha (1984). The dialectic of arithmetic in grocery shopping. In B. Rogoff and J. Lave (Eds.), Everyday Cognition: Its Development in Social Context, pp. 67-94. Cambridge, MA: Harvard University Press.

Lave, J., S. Smith, and M. Butler (1989). Problem solving as an everyday practice. In R. I. Charles and E. A. Silver (Eds.), The Teaching and Assessing of Mathematical Problem Solving, pp. 61-81. Hillsdale, NJ: Lawrence Erlbaum. 
Lave, J. and E. Wenger (1991). Situated Learning: Legitimate Peripheral Participation. Cambridge: Cambridge University Press.

Layder, D. (2006). Understanding Social Theory (Second Ed.). London: Sage.

Lynch, M. (1995). The idylls of the academy. Social Studies of Science 25 (3), 582600.

Martin, M. (2000). Verstehen: The Uses of Understanding in Social Science. New Brunswick, NJ: Transaction.

Murtaugh, M. (1985a). A Hierarchical Decision Process Model of American Grocery Shopping. Ph. D. thesis, University of California, Irvine.

Murtaugh, M. (1985b). The practice of arithmetic by American grocery shoppers. Anthropology and Education Quarterly 16 (3), 186-192.

Osterlund, C. and P. Carlile (2005). Relations in practice: sorting through practice theories of knowledge sharing in complex organizations. The Information Society 21 (2), 91-107.

Rose, E. (1960). The English record of a natural sociology. American Sociological Review 25 (2), 193-208.

Rubinstein, D. (2001) Culture, Structure, and Agency: Toward a Truly Multidimensional Sociology. London: Sage.

Sacks, H. (1975). Everyone has to lie. In M. Sanches and B. G. Blount (Eds.), Sociocultural Dimensions of Language Use, pp. 57-79. New York: Academic Press.

Sawyer, R. (2005). Social Emergence: Societies as Complex Systems. Cambridge: Cambridge University Press.

Schutz, A. (1962). Collected Papers I. The Hague: Martinus Nijhoff.

Schutz, A. (1964). Collected Papers II. The Hague: Martinus Nijhoff.

Schutz, A. (1966). Collected Papers III. The Hague: Martinus Nijhoff.

Schatzki, T. R., K. Knorr-Cetina, and E. von Savigny (Eds.) (2001). The Practice Turn in Contemporary Theory. London: Routledge.

Sewell, W. H. (1992). A theory of structure: duality, agency, and transformation. American Journal of Sociology 98 (1), 1 -22.

Spiegelberg, H. (1960). The Phenomenological Movement: A Historical Introduction (Two Volumes). The Hague: Martinus Nijhoff.

Suchman, L. A. (1987). Plans and Situated Actions: The Problem of Human-Machine Communication. Cambridge: Cambridge University Press.

Throop, C. J. and K. M. Murphy (2002). Bourdieu and phenomenology: a critical assessment. Anthropological Theory 2 (2), 185-207. 